\title{
PV System based Zeta Converter with Three-Phase Inverter For High-Speed BLDC Motor Applications
}

\author{
Dr B Meenakshi ${ }^{1}$, G Jayaprakash ${ }^{2}, \mathrm{~N}_{\text {Logeswari }}{ }^{3}$ \\ \{meenakshi.eee@sairam.edu.in ${ }^{1}$,jayaprakashjp1794@gmail.com², logeswari.ece@sairam.edu.in ${ }^{3}$ \} \\ ${ }^{1}$ Professor/ EEE Department, Sri Sairam Engineering College; Chennai, India, ${ }^{2}$ PG Student, Sri \\ Sairam Engineering College ,Chennai, India, ${ }^{3}$ Assistant Professor/ ECE department, Sri Sairam \\ Engineering College, Chennai, India
}

\begin{abstract}
In this paper, for BLDC drive based configuration the sliding mode control scheme, power converter based renewable system is presented in this paper. The PV system is proposed to provide input source for the SMC based system. The proposed control method is used based on the vector control. According to this, the drive system behaviour of the speed control capacity is enhanced. To improve the system input source which fed from PV system, the ZETA converter is proposed. The speed and torque of the motor can be controlled by the SMC method based on vector control. The results of the proposed system are obtained and verified using the MATLAB/Simulink.
\end{abstract}

Keywords: Zeta converter, PV system, BLDC drive, sliding mode controller, speed control.

\section{Introduction}

For our everyday lives, electricity is important. In tradition, power generation requires the burning of fossil fuels, resulting in serious problems for humans and for the atmosphere of planet Earth. Consequently, efforts have increasingly been centered on seeking solutions for producing power from sunlight. PV systems are an extremely reliable and relatively cheap alternative solution for electricity generation, particularly in areas with multiple sunshine hours per day.

Even so, in recent times a substantial decrease in the manufacturing and installation costs of panes has led not only to solar power cultivation by panel rooftop systems but also to a move towards wide photovoltaic systems in several countries around the world. PV systems have been commonplace in power system applications over the past few years and played a large role in new century electricity generation. Whenever the sun light rays enter the PV module, the PV system transforms sunlight directly into electricity. The efficiency of the solar photovoltaic system strongly relates factors such as the geometric position of the sun, the atmospheric temperature and sunlight.

Sunlight can be turned into electric power which can be used, saved or linked immediately to the grids by photovoltaic (PV) systems. The actual cost of installing PV systems is generally reasonably large. Moreover, the power transmission process is relatively poor in PV systems. Solar energy is the greatest source of clean, inexhaustible electricity. When correctly used, it will satisfy much of the world's energy requirements. The power of the world is around $1.8 \times 1011 \mathrm{MW}$ from the sun. It is however quite difficult how to reliably 
assess the performance properties of photovoltaic cells and optimize the output of photovoltaic systems under different weather conditions. The full power point control activity is also referred to as MPPT.

The key downside of a PV system, however, is poor performance. Thus multiple MPPT approaches are developed to derive full power from the PV module. The MPPT algorithms are also available. The $\mathrm{P} \& \mathrm{O}$ adaptive approach radically adjusts the step size depending on the disparity in power between two disturbances. Even so, the ratio of the step-size and power differential must be calculated as per the particular model to obtain the best results. The converter will differ with the duty ratio by adjusting the input amplitude. If the output impedance of a PV system is aligned with the input signal of the regulator, the maximum power could be improved.

In the industrial and vehicles sectors the speed drives are normally used. The PMSM motors are used in those drives for recent years. BLDC's fuel consumption is very low, and is therefore used in green vehicles. Electric and hybrid car recognition boosts PMSM due to their high efficiency, excessive power density, compact structure and fast dynamic response, Permanent Magnet Synchronous Motor was an increasing number of uses in electric vehicle applications. The PMSM motors are used in many fields of automation, and applications such as precision machining, metal cutting, robot etc.

The speed of the PMSM can be controlled by many methods of control up to now PID control, adaptive control method etc., are used. In the conventional systems, the PMSM motors used digital signal processor (DSP) in most literatures. But the DSP systems are affected due to the resource exhaustion in CPU development with long time. Many control techniques are used in PMSM motors possibly for the applications with high performance where the DC drives were conventionally used. Previously the vector control is utilized to control the PMSM as the operation of the DC motor which have separately excitation with the armature of current regulation. Here the armature current and torque in directly proportional with the flux of excitation. In this motor, the component of torque current can be controlled to accomplish the torque control with independently control of the component of flux current.

\section{Related works}

PV systems have become indispensable part in the field of electric power generation. Time to time there have been a series of improvement made in this field. A novel auto balancing control for magnetically suspended high speed motor which attenuates unbalanced vibration at high precision was proposed by Zheng [1]. The use of ZETA converter to feed the BLDC drives for hysteresis to speed control is implemented [2]. The idealistic use of storing kinetic energy in batteries instead of wasting it using proportional integral controller and fuzzy logic controller results in smooth transition and efficient energy conservation [3]. The performance analysis of SMC based rotor and stator have yielded better thermal capability. The magnetic field, flux distribution and current density of the core also increased in performance [4]. The interleaved boost converter coupled directly with the inductors have drastically reduced the ripple [5]. The use of 3 phase switching with TAF to reduce switching number in sampling period and commutation torque ripple [6]. The Solar Power Technology has a great viable economic impact as it can provide maximum intermediate power tracking and maximum electricity supply to the grid [7]. Sun in his paper proposed a SSRM with exciting and auxiliary stator pole and discrete series of rotor segments which improved the 
performance like higher output torque, lower ripple etc [8]. The Fault tolerance control (FTC) is very critical in terms of safety especially in a system involving actuators such as EVs. AFTSMFTC is the used to eliminate such faults caused by the actuators. It also not only selfadjusts but also reduce chattering resulting in higher accuracy [9]. By reducing the voltage stress across the power switch using a activated switch load capacitor block the DC-DC boost converter have been proven theoretically could generate a 70 times higher voltage than that of its input [10]. The jumping behaviour can cause various consequences hence these parameter estimations must be done. The use of switching controller based on switching model reduce parameter dependence and fast response [11]. The switching performance of the switch can be improved by using a lossless snubber cell for Buck boost converter. This proposed method by Joo\& Han have enabled BBC to operate at high switching frequencies with higher efficiencies [12]. These concurrent improvements in technologies have direct influence over the years which is not only being separated as such from production and distribution but also includes on its applications especially motors.

\section{Proposed System}

In this proposed system the drive is controlled by SMC regulator which is utilized to provide efficient robust control for dynamic and complex system that is working depends on the varying conditions. As shown in fig. 1 the SMC controller based proposed BLDC drive is controlled and the Anfis control signals are provided to the high gain zeta converter. The feedback voltage from the inverter is fed to the proposed SM controller to generate switching signals for the power switching devices which are used in VSI. The pulse generation leads the BLDC motor operating performance through the voltage and current control.

In this proposed system, BLDC motor is used in electric vehicle with the speed and torque control of the SMC control which performs the motor control through providing VSI converter using park and Clarke transformations and vector control. The SMC control is achieving dynamic response control of system by means of change of flux reference as well as obtained flux rotor position. The proposed BLDC based control of speed is shown in fig. 1 with block diagram. The ZETA converter is used to achieve the improvement of the DC link voltage of the proposed system. The DC supply is given to the BLDC motor along with the voltage source inverter and the power conversion of zeta converter which is used to achieve high DC link voltage at the input of the inverter.

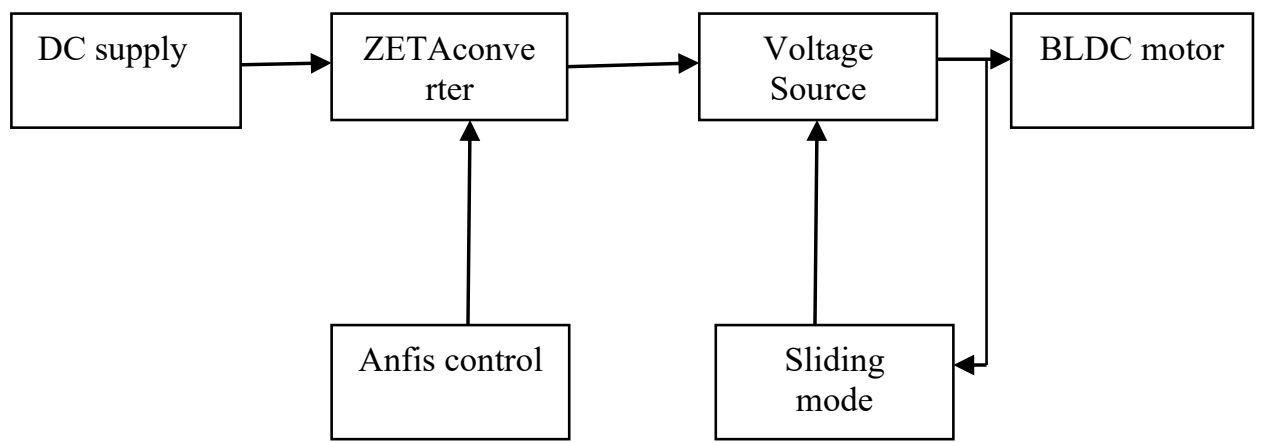

Fig 1: Block Diagram of the proposed system 


\subsection{PV Source:}

A photovoltaic system is an arrangement of components designed to supply usable electric power for a variety of purposes, using the Sun as the power source as shown in Fig. 2. This shows the widely used PV solar cell equivalent circuit. The present source's intensity is exactly equal to the cell light. As the load resistance increases, the solar cell cannot sustain a fixed current.

IL

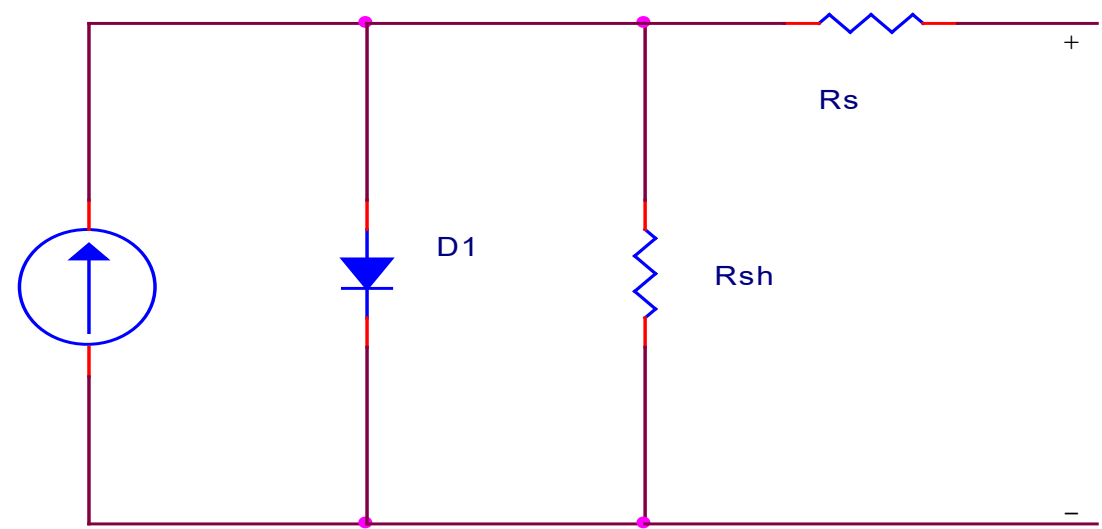

Fig 2: PV Single Diode Model

\subsection{ZETA converter:}

In this system, the ZETA converter is proposed as shown in fig. 3 to control the DC link voltage regulation and the output response of the converter is fed to the inverter which is providing $\mathrm{AC}$ voltage for induction motor. The proposed converter comprises of two capacitors as well as inductors. High voltage gain is achieved through the power switch duty cycle and dc link capacitor operation. The operation of converter is when the power switch is conducting, the $\mathrm{D}$ is turned to off state then in this charging mode the $\mathrm{V}_{\mathrm{s}}$ providing current to the L1 and L2 inductors. During the switch S turned off, D comes to conduction the stored power in the inductor L2 is fed to load.

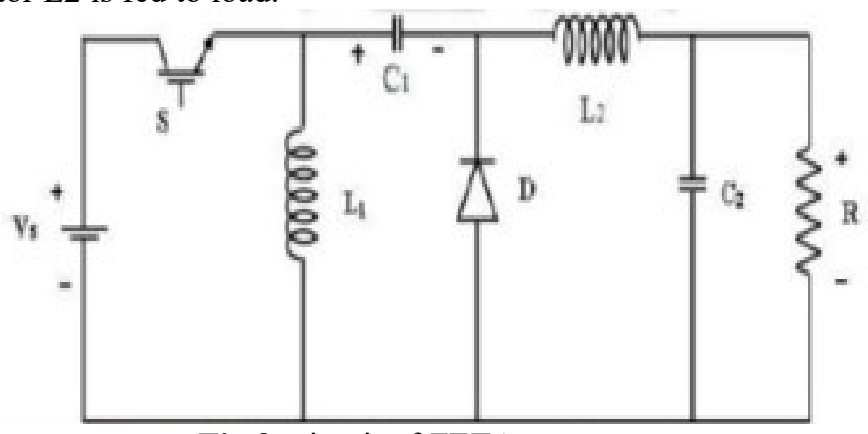

Fig 3: circuit of ZETA converter

ZETA is a fourth-order, multi-real, dynamic poles and zeros converter. The ZETA converter has no right-half plane zero with the exception of the SEPIC converter and could be more conveniently offset for greater loop efficiency and improved load transfer performance for lower output power values. 


\section{Control method:}

In this proposed system the drive is controlled by SMC regulator which is utilized to provide efficient robust control for dynamic and complex system that is working depends on the varying conditions. The proposed control of SMC based system is shown in fig.4. This control method is efficiently maintaining the system performance with consistent and better stability. The SMC surface is derived as,

$$
\sigma(x)=\left(\frac{d}{d t}+\lambda\right)^{r-1}\left(x^{*}-x\right)
$$

The sliding mode controller architecture involves choosing the sliding base, as well as the control rules. If the system states reach the sliding phase, the dynamics of the mechanism are defined by the chosen sliding surface and are robust to all the disruptions and variations in the parameters. Because SMC refers to the first-order method, the SMC uses the noise-sensitive acceleration signal. At every time, the status of such switching signals is defined by the direction of the rotor, the error in speed and the winding currents. The magnitude and frequency of the output voltage of the inverter depends on the switching signals produced by the control hysteresis.

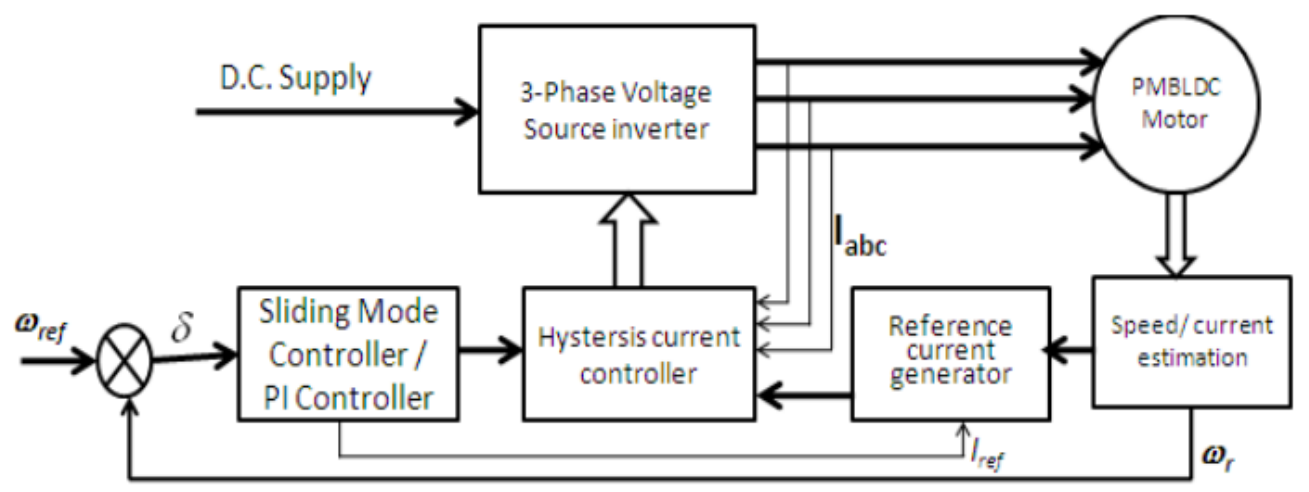

Figure 4:Block diagram of the planned system control of SMC

\section{Simulation and Results}

The fig. 5 shows that the proposed BLDC drive based on the voltage source inverter SMC control simulation for speed and torque range control. The DC supply is given as a input source $12 \mathrm{~V}$. The given input source is fed to propose zeta converter which consists of reduced amount of active components that improve the source voltage as well as that ensures the constant DC link voltage. The anfis control is used to proposed converter power switch of conversion side that means DC-DC conversion. In the simulink model of the proposed system contains the DC source for zeta converter which has a switching device and is controlled by the pulse generator. The PWM signals are generated by using the pulse generator block. The 
output of the converter is stored in DC link voltage. The below part of the model is representing the proposed controller design.

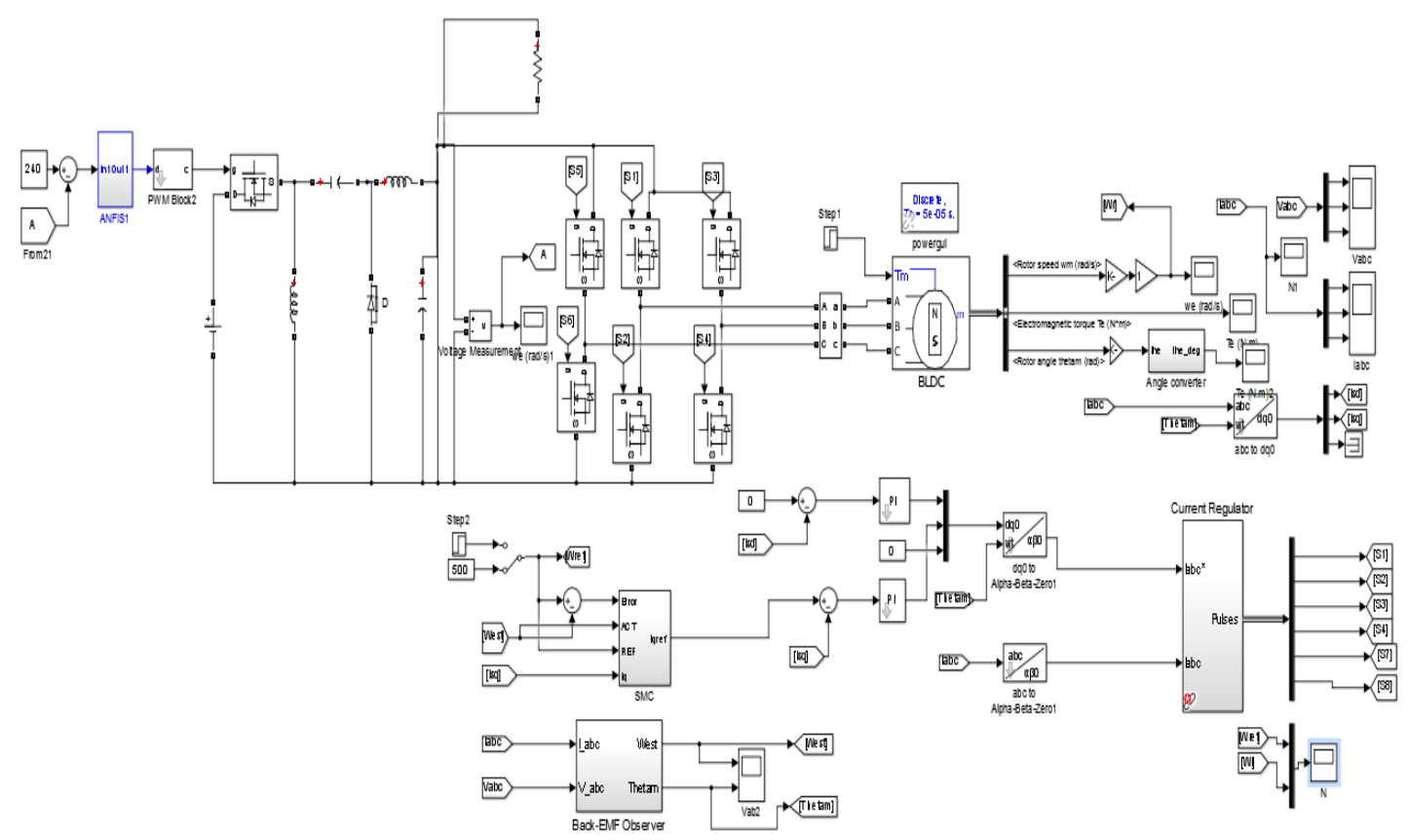

Fig 5: Proposed System Simulation

The six power switches of the inverter side are controlled by using the proposed back emf estimation method. According to this method, the speed of the drive and torque range can controlled widely. The waveforms for the input voltage, Dc bus voltage, inverter voltage, and drive speed are shown in following figures.

The input supply voltage for the given input source is $12 \mathrm{~V}$ as shown in below fig. 6 and the supply voltage is after improved by the DC- DC zeta converter as shown in fig. 7. 


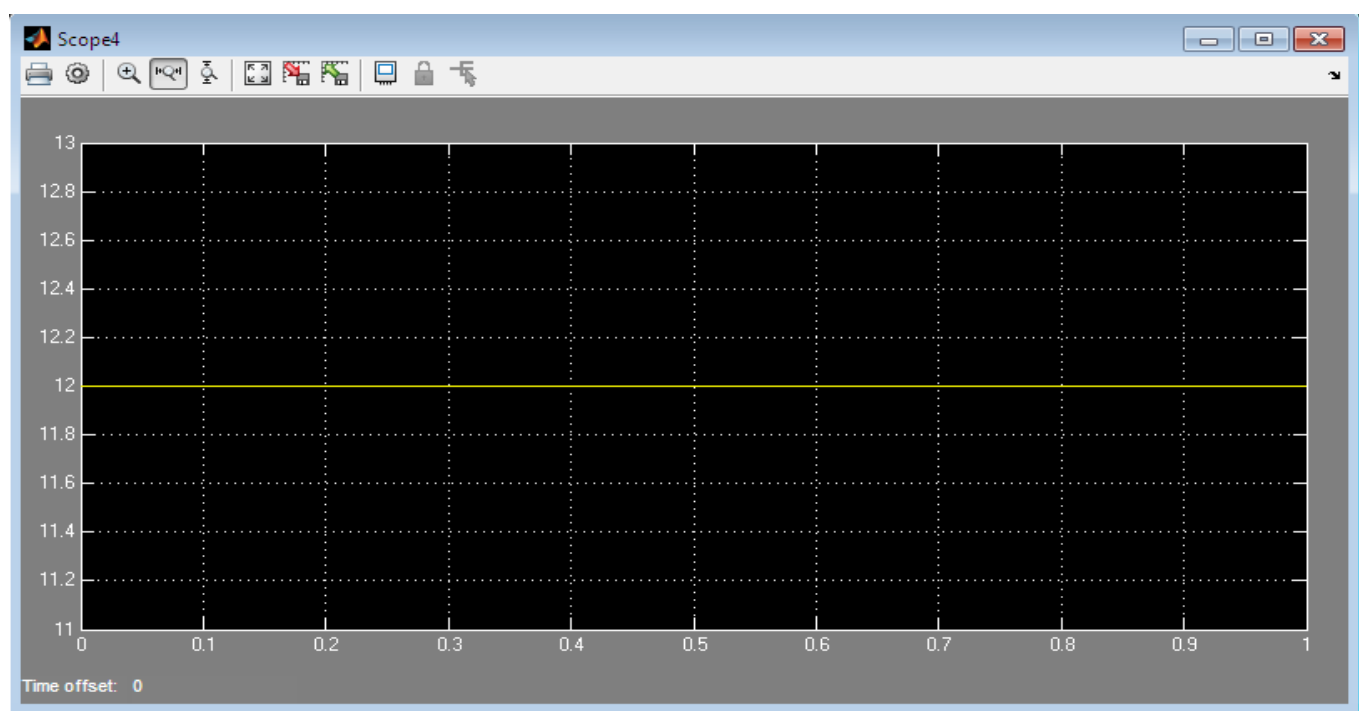

Fig 6: Proposed System Input Voltage

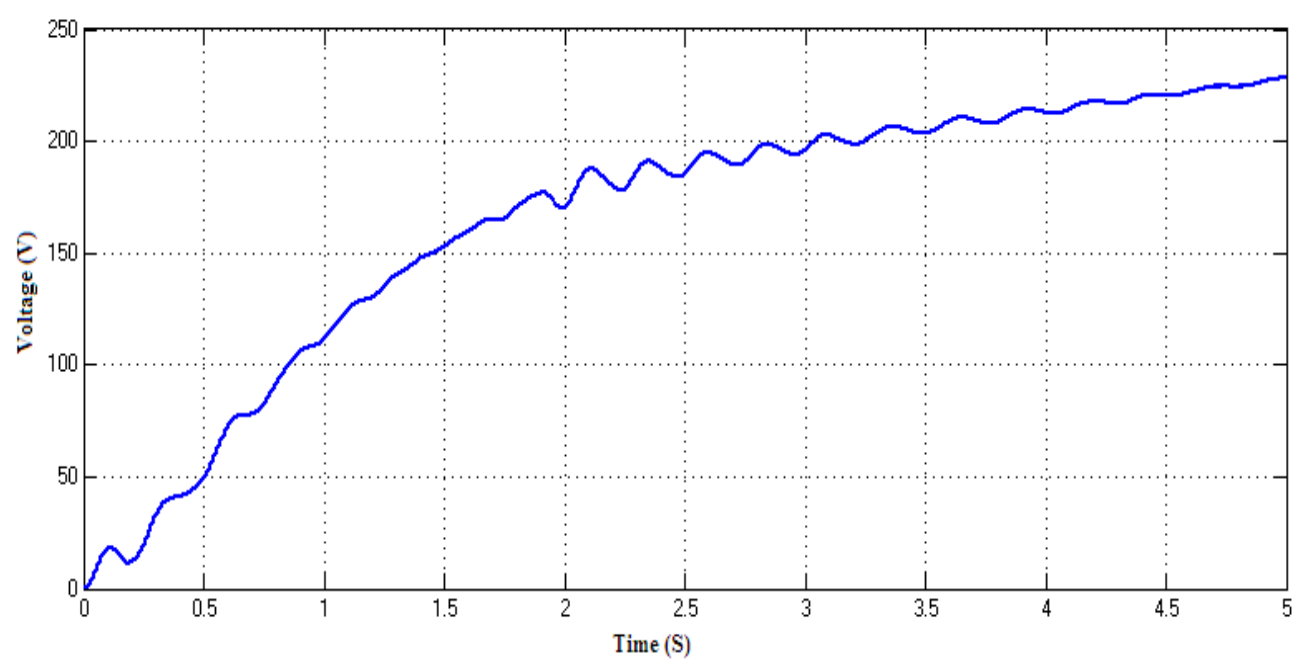

Fig 7: DC link bus voltage 


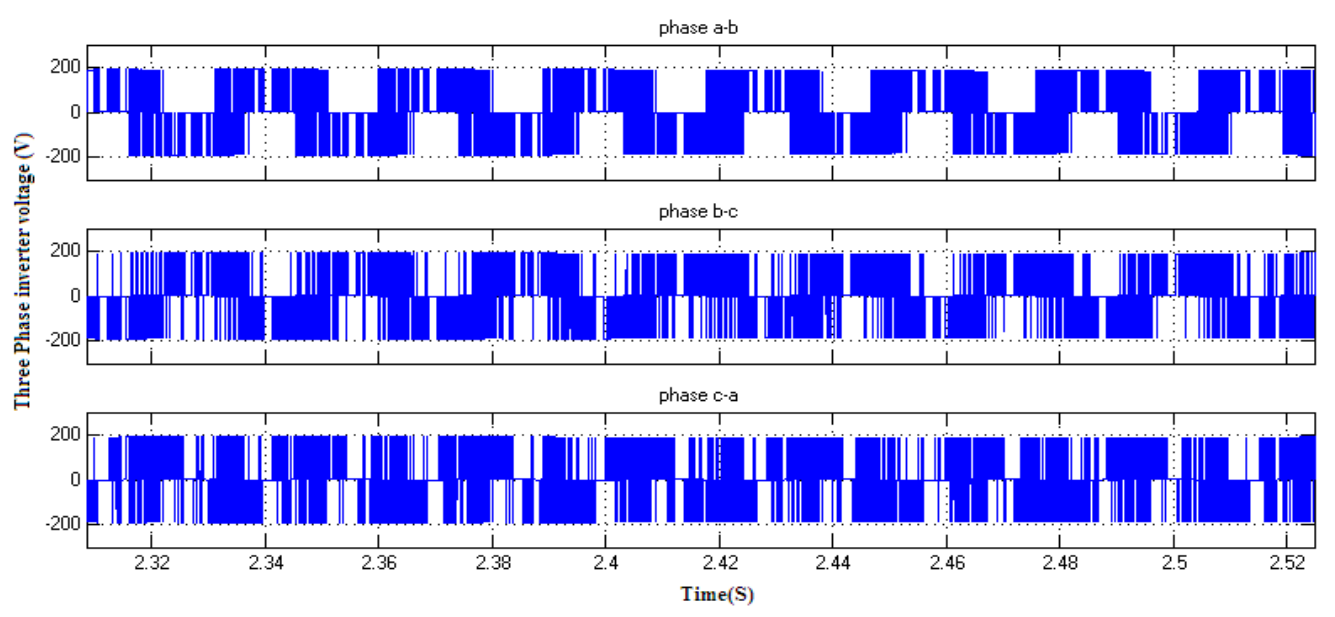

Fig 8: Inverter Output voltage

The inverter output is shown in fig. 8 the output of the proposed inverter is before using LC filter. The fig. 9 illustrates the drive stator current.

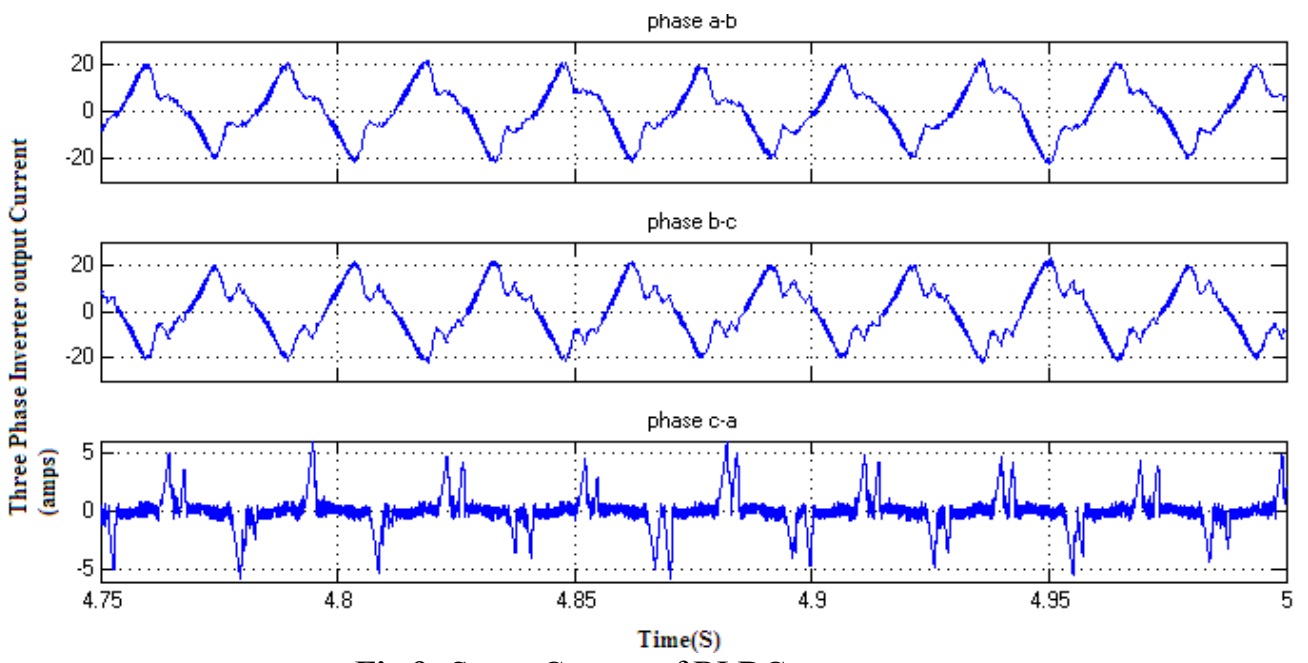

Fig 9: Stator Current of BLDC motor

The speed of the proposed system is controlled and the speed of the BLDC motor is 500 revolution per minute (RPM). The motor speed is settled in quickly by means of SMC controller. The settling time of the proposed system is $0.7 \mathrm{sec}$. The ripples also reduced. The fig. 10 is showing that the BLDC drive speed which is controlled and settled quickly. The fig.11 torque of the proposed drive. 


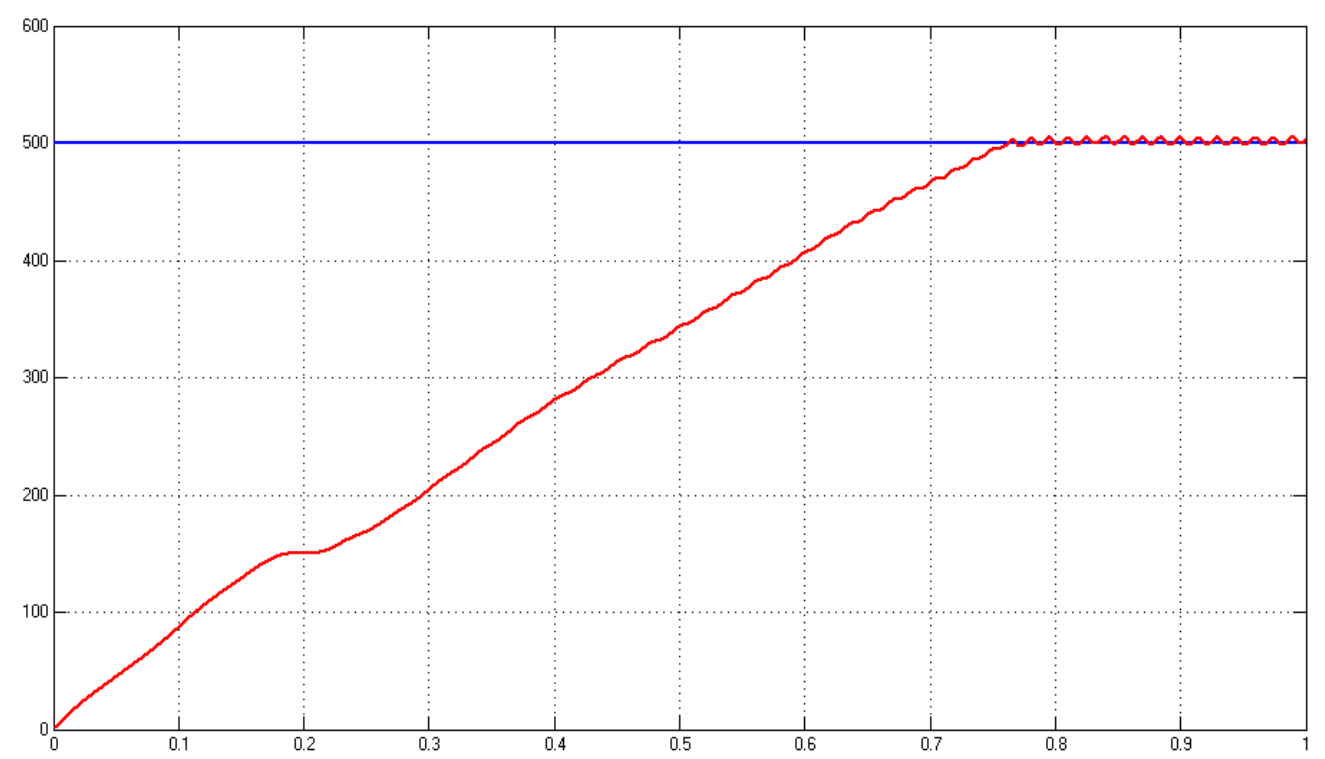

Fig 10: Speed of the BLDC drive

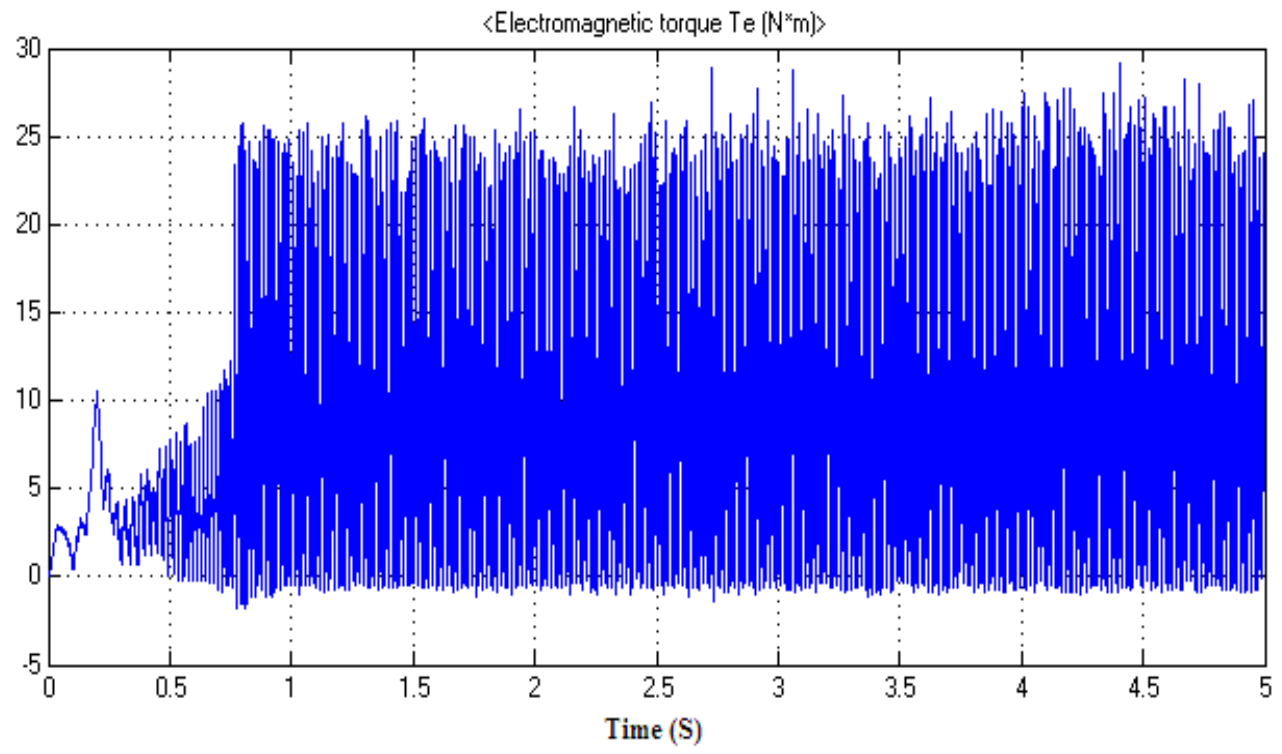

Fig 11: Torque of the BLDC drive

\section{Conclusion}

In this paper, the BLDC drive based on zeta converter is implemented with the sliding mode control is proposed. The speed of the drive can be regulated using with proposed controllers. The drive speed and efficiency is improved and the dc supply voltage is improved 
by zeta converter. The voltage boosting method and the efficiency of this proposed method is high while compared with traditional systems. The results for the proposed system are obtained successfully using simulink model and shown the output of the input voltage, output of the BLDC motor speed which controlled using sliding mode system. The results are verified and examined in MATLAB/Simulink and it shows that motor torque range and speed enlargement.

\section{References}

[1] Zheng, S., Han, B., Feng, R., \& Jiang, Y. (2015). Vibration suppression control for AMBsupported motor driveline system using synchronous rotating frame transformation. IEEE Transactions on Industrial Electronics, 62(9), 5700-5708.

[2] Manie, N., \&Pattanaik, B. (2019). Zeta DC-DC converter based on MPPT technique for BLDC application. International Journal of MC Square Scientific Research, 11(2), 1-12.

[3] Anjana, R. (2019, Feb). Fuzzy and PI Based Speed Control of BLDC Motor using Bidirectional Converter for Electric Vehicle Application. Trends in Electrical Engineering, $8(3), 35-45$.

[4] Rajkumar, S., Sundaram, C. S., Sedhuraman, K., \&Muruganandhan, D. (2019, March). Performance Analysis of Hub BLDC Motor Using Finite Element Analysis. In 2019 IEEE International Conference on System, Computation, Automation and Networking (ICSCAN) (pp. 1-5). IEEE.

[5] Ramaprabha, R., Balaji, K., Raj, S. B., \&Logeshwaran, V. D. (2013). Comparison of interleaved boost converter configurations for solar photovoltaic system interface. The Journal of Engineering Research [TJER], 10(2), 87-98.

[6] Yadav, D., Parekh, U., Patel, K., Parmar, R., \& Prakash, M. (2019). Application of Modified Three Phase Conduction Method to Minimize Torque Ripple in BLDC Motor. IJRARInternational Journal of Research and Analytical Reviews (IJRAR), 6(1), 155-156.

[7] Balachandra, P., \&Manjula, P. (2019, March). Maximum Intermediate Power Tracking for Renewable Energy Service. In International Conference on Emerging Current Trends in Computing and Expert Technology (pp. 462-468). Springer, Cham.

[8] Sun X, Diao K, Yang Z. Performance improvement of a switched reluctance machine with segmental rotors for hybrid electric vehicles. Computers \& Electrical Engineering. 2019 Jul 1;77:244-59.

[9] Guo B, Chen Y. Robust adaptive fault tolerant control of four wheel independently actuated electric vehicles. IEEE Transactions on Industrial Informatics. 2019 Jan 1.

[10] Qi, Q., Ghaderi, D., \& Guerrero, J. M. (2021). Sliding mode controller-based switchedcapacitor-based high DC gain and low voltage stress DC-DC boost converter for photovoltaic applications. International Journal of Electrical Power \& Energy Systems, 125, 106496.

[11] Taheri, A., Ghasemian, A., \&Ren, H. P. (2020). Sliding mode control of Boost converter with jump flow switched system. Journal of the Franklin Institute, 357(18), 13734-13752.

[12] Joo, H. I., \& Han, S. K. (2020). Lossless Snubber Cell for a Soft-Switched Bidirectional BuckBoost Converter. IEEE Access, 8, 165708-165719. 